\title{
Efeito de diferentes níveis de adubação foliar com NPK mais micronutrientes na produtividade do milho safrinha na Região de Dourados/MS
}

\author{
Effect of different levels of foliar fertilization with NPK \\ micronutrients more in the productivity of winter maize in \\ Dourados Region, Mato Grosso do Sul, Brazil
}

\author{
Guilherme Augusto Biscaro ${ }^{1}$; Eber Augusto Ferreira do Prado $^{2 *}$; \\ Anamari Viegas de Araujo Motomiya ${ }^{1}$; Antonio Dias Robaina ${ }^{1}$
}

\section{Resumo}

\begin{abstract}
Objetivou-se avaliar o efeito da adubação foliar nas características agronômicas de plantas de milho, irrigado por um sistema de irrigação por aspersão convencional. O experimento foi conduzido na Faculdade de Ciências Agrárias da Universidade Federal da Grande Dourados (UFGD), no período de 23 setembro de 2008 a 20 fevereiro de 2009 utilizando-se um fertilizante líquido multinutriente NPK + micronutrientes. O delineamento experimental utilizado foi blocos casualizados, com nove doses do fertilizante líquido $\left(0 ; 0,25 ; 0,50 ; 0,75 ; 1,0 ; 1,25 ; 1,5 ; 1,75\right.$ e $\left.2,0 \mathrm{~L} \mathrm{ha}^{-1}\right)$ e quatro repetições. As plantas de milho foram avaliadas no decorrer do experimento entre os estádios fenológicos R3 à R6 caracterizados pelo estado de grão farináceo e maturação fisiológica respectivamente. As variáveis analisadas foram altura de plantas, altura de inserção das espigas, número de grãos por espiga e produtividade. A adubação foliar proporcionou aumento da altura das plantas de milho, redução da altura de inserção das espigas, aumento do número de grãos por espiga e da produtividade. A dose estimada de $1,15 \mathrm{~L} \mathrm{ha}^{-1}$ proporcionou os melhores resultados sobre as variáveis analisadas.
\end{abstract}

Palavras-chave: Zea mays, nutrição de plantas, fertilizante líquido, NPK

\begin{abstract}
The objective was to evaluate the effect of foliar fertilization on the agronomic characteristics of corn plants, irrigated by a system of irrigation by sprinkler. The experiment was conducted at the Faculty of Agrarian Sciences, Federal University of Grande Dourados (UFGD), from 23 September 2008 to February 20, 2009 using a multinutrient liquid fertilizer NPK plus micronutrients. The experimental design was randomized blocks with nine doses of liquid fertilizer $(0,0.25,0.50,0.75,1.0,1.25,1.5,1.75$ and $2.0 \mathrm{~L} \mathrm{ha}^{-1}$ ) and four replications. The corn plants were evaluated during the experiment between growth stages R3 to R6 characterized by the state of the dough and physiological maturity, respectively. The variables studied were plant height, height of ear insertion, number of grains per ear and yield. The foliar provided to increase the height of corn plants, reducing the height of insertion of the ears, increasing the number of grains per ear and yield. The estimated dose of $1.15 \mathrm{~L} \mathrm{ha}^{-1}$ provided the best results on the variables analyzed.
\end{abstract}

Key words: Zea mays, plants nutrition, liquid fertilizer, NPK

\footnotetext{
${ }^{1}$ Profs. Adjunto(s) da Universidade Federal da Grande Dourados, UFGD. Rod. Dourados, Itahum, Km 12, Zona Rural, 79800-000, Dourados, MS. E-mail: guilhermebiscaro@ufgd.edu.br; anamarimotomiya@ufgd.edu.br; antoniorobaina@ufgd.edu.br

2 Discente de Doutorado em Agronomia, Programa de Pós-graduação em Agronomia, UFGD, Dourados, MS. E-mail: eberprado@, hotmail.com

* Autor para correspondência
} 


\section{Introdução}

O milho (Zea mays L.) é uma das culturas de maior importância para o Brasil, não só do ponto de vista econômico, em função da extensa área cultivada, mas também nutricional, em razão da diversidade de utilização, em que se destacam a alimentação humana e animal (DÖBEREINER; BALDANI; BALDANI, 1995) e (FANCELLI; NETO, 2000). A cultura desempenha papel fundamental na agricultura brasileira tanto do ponto de vista econômico, em função da extensa cadeia produtiva e por ser uma commodities em ascensão no mercado internacional, como do ponto de vista agronômico, compondo o sistema de rotação de cultura (BONO et al., 2008).

Nos últimos anos, a cultura do milho, no Brasil, vem passando por importantes mudanças no manejo e tratos culturais, o que tem resultado em aumentos significativos na produtividade de grãos. Entre essas mudanças, destacam-se a adoção de sementes de cultivares com maior potencial de produção, alterações no espaçamento e na densidade de semeadura de acordo com as características das cultivares e melhoria na qualidade dos solos e na fertilização (YAMADA; ABDALLA; VITTI, 2007; VON PINHO et al., 2009).

A necessidade nutricional das plantas é também um fator que deve ser considerado, quando o objetivo é aumentar a produção de grãos. O milho responde progressivamente à adubação, desde que os demais fatores estejam em níveis ótimos, sendo que o nitrogênio é o nutriente que apresenta maior resposta de aumento de produtividade de grãos (SANGOI; SILVA; ARGENTA, 2004). Normalmente, os agricultores que obtêm alta produtividade $\left(\mathrm{kg} \mathrm{ha}^{-1}\right)$ de milho, aplicam altas doses de fertilizantes $(\mathrm{N}, \mathrm{P}$, $\mathrm{K})$, geralmente acima dos níveis recomendados em suas regiões (COELHO; CRUZ; PEREIRA FILHO, 2004).

A eficiência do uso do nitrogênio $(\mathrm{N})$ em cereais no mundo é de apenas 33\%. Considerando os $67 \%$ de $\mathrm{N}$ que não são aproveitados, tem-se um custo anual substancial em fertilização nitrogenada (RAUN; JOHNSON, 1999), em adição aos prováveis impactos negativos ao ambiente (SCHRÖDER et al., 2000). Segundo Carvalho et al. (2001), a maioria dos produtores de grãos reconhece a necessidade de um programa correto de manejo de nutrientes aplicados ao solo para alcançar as metas de produtividade. Pouco se conhece sobre as situações nas quais os fertilizantes foliares podem complementar os fertilizantes aplicados via solo, visando ao aumento da eficiência de uso do nutriente, da produtividade e lucratividade.

Nos adubos foliares encontrados comercialmente, o $\mathrm{N}$ quase sempre está presente nas misturas com micronutrientes. Argumenta-se que a aplicação foliar é um meio eficiente de se fornecer $\mathrm{N}$ às plantas. Neste contexto, a uréia auxiliaria a absorção dos micronutrientes contidos na solução aplicada nas folhas, resultando em maior desenvolvimento e produtividade das plantas (BOARETTO et al., 1999). No entanto, pouco se conhece da aplicação de uréia via foliar como fonte isolada de $\mathrm{N}$ durante o estádio vegetativo de plantas de milho.

A adubação foliar assegura que os fertilizantes sejam aplicados diretamente na região de maior concentração de raízes das plantas, permitindo o fracionamento das doses e o aumento na eficiência da adubação. De acordo com resultados de Coelho, Cruz e Pereira Filho (2004) ao estudarem diferentes métodos de adubação foliar afirmaram que, a adubação foliar pelo método convencional, gera um aumento na eficiência de aproveitamento de nutrientes, despendendo-se 20 a 50\% menos fertilizantes que com o método convencional.

Segundo os resultados de Von Pinho et al. (2009) afirmaram que pesquisas que visam a avaliar o comportamento agronômico de cultivares de milho em diferentes densidades de semeadura sob diferentes doses de fertilizantes são necessários e podem fornecer valiosas informações aos produtores.

O objetivo desta pesquisa foi de verificar a 
viabilidade do uso da adubação foliar, utilizando um fertilizante liquido (NPK + micronutrientes), na cultura do milho. Para isso, avaliou-se a resposta das características agronômicas da cultura submetida a diferentes doses do fertilizante solúvel.

\section{Material e Métodos}

A pesquisa foi conduzida entre setembro de 2008 e fevereiro de 2009, na Faculdade de Ciências Agrárias (FCA), Universidade Federal da Grande Dourados (UFGD), município de Dourados/MS. A altitude local é de $446 \mathrm{~m}$, com latitude de $22^{\circ} 11^{\prime}$ $45^{\prime}$ 'S e longitude $54^{\circ} 55^{\prime} 18^{\prime}$ 'W. O clima da região, de acordo com a classificação de Köppen, é do tipo Cwa (mesotérmico úmido), com verão chuvoso e inverno seco. Durante a condução do experimento, a temperatura média observada foi de $24,7{ }^{\circ} \mathrm{C}$, e a umidade relativa média do ar foi de $68,8 \%$. A precipitação total foi de $775,5 \mathrm{~mm}$. Não ocorreu nenhuma anormalidade climática durante o ciclo da cultura.

O solo da área experimental foi classificado como Latossolo Vermelho distroférrico, de textura argilosa, com $30 \%$ de areia, $60 \%$ de argila e $10 \%$ de silte. Antes da instalação do experimento, foram coletadas amostras de solo da camada de 0 a $20 \mathrm{~cm}$ de profundidade, que apresentaram as seguintes características químicas: $1,0 \mathrm{mg} \mathrm{dm}^{-3}$ de $\mathrm{P} ; 27,5 \mathrm{~g}$ $\mathrm{dm}^{-3}$ de MO; 5,0 pH em $\mathrm{CaCl}^{2} ; 5,2 ; 0,6 ; 41,0 ; 25,0$; 55,$0 ; 126,2 ;$ mmolc dm ${ }^{-3}$ de $\mathrm{K}, \mathrm{Al}, \mathrm{Ca}, \mathrm{Mg}, \mathrm{H}+\mathrm{Al}$, CTC; 19,8; 62,6; 94,6; 2,2 mg dm ${ }^{-3}$ de Cu, Mn, Fe, $\mathrm{Zn}$, respectivamente, e $56 \%$ de saturação por bases.

Utilizou-se neste trabalho o milho híbrido duplo com nome comercial de $\mathrm{CARGO}^{\circledR}$, de ciclo precoce, com cor de grão alaranjado e textura dura, desenvolvido pela Syngenta. Segundo a Fundação MS, este híbrido é um dos recomendados para o Estado de Mato Grosso do Sul. A semeadura foi realizada no dia 23 de setembro de 2008 por uma semeadora de cinco linhas a vacum, utilizando-se 55000 sementes por hectare. A adubação de base foi de $250 \mathrm{~kg} \mathrm{ha}^{-1}$ da formula 10-30-10 (NPK).
O delineamento experimental foi em blocos casualizados (DBC), com nove doses do fertilizante líquido $(0 ; 0,25 ; 0,50 ; 0,75 ; 1,0 ; 1,25 ; 1,5 ; 1,75$ e 2,0 $\left.\mathrm{L} \mathrm{ha}^{-1}\right)$. Foi realizada apenas uma aplicação, aos 24 dias após a emergência (DAE) da cultura, estando esta no estádio V6. O fertilizante líquido utilizado foi NIPHOKAM $108^{\circledR}$, que possui a seguinte concentração de macro e micronutrientes: $10 \%$ de $\mathrm{N} ; 8 \%$ de $\mathrm{P}_{2} \mathrm{O}_{5} ; 8 \%$ de $\mathrm{K}_{2} \mathrm{O} ; 0,5 \%$ de $\mathrm{Mg} ; 1 \%$ de $\mathrm{Ca}$; $2 \%$ de $\mathrm{S} ; 1 \%$ de $\mathrm{Zn} ; 0,5 \%$ de B; $0,1 \%$ de Fe; $0,1 \%$ de $\mathrm{Mo} ; 0,2 \%$ de $\mathrm{Cu}$ e $0,5 \%$ de $\mathrm{Mn}$.

Cada parcela possuía seis metros de largura com cinco metros de comprimento com espaçamento entre linhas de $0,90 \mathrm{~m}$. O preparo do solo foi realizado dez dias antes da semeadura com uma gradagem pesada e uma leve.

O sistema de irrigação utilizado foi por aspersão convencional com linha lateral de PVC, com 50 $\mathrm{mm}$ de diâmetro, instalada em nível. $\mathrm{O}$ manejo da irrigação foi realizado com base na metodologia sugerida por Bernardo (1989); Bernardo, Soares e Mantovani (2005), informações obtidas pelo tanque "Classe A" e os dados de Kc nos diferentes estágios da cultura. Devido aos problemas de operacionalidade de se aplicar diferentes doses de um produto em parcelas instaladas em uma mesma área irrigada, e para se ter um controle mais preciso da quantidade do produto a ser aplicada em cada uma delas, foi utilizado um aplicador do tipo costal, com vazão de $40 \mathrm{~L} \mathrm{~h}^{-1}$, com as dose propostas neste trabalho. A aplicação era realizada logo após a irrigação normal da área, com uma lâmina de 15 $\mathrm{mm}$.

No momento da aplicação o milho estava com cinco a seis folhas totalmente formadas. As condições no momento da aplicação eram de céu claro com velocidade do vento inferior a $5,0 \mathrm{~km}$ por hora, temperatura do ar de $26^{\circ} \mathrm{c}$ e umidade relativa média de $70 \%$.

A colheita foi realizada no dia 13 de fevereiro de 2009, sendo o ciclo total da cultura de 144 dias. Foram coletadas 10 plantas na área útil de cada 
parcela para determinação dos componentes da produção (altura de plantas, diâmetro do colmo, altura de inserção das espigas, número de grãos por espigas, massa de 100 grãos e produtividade). Após a debulha das espigas, os grãos foram pesados e a umidade foi corrigida para $13 \%$, obtendo-se a produtividade de grãos em $\mathrm{kg} \mathrm{ha}^{-1}$.

Os resultados foram submetidos à análise de variância. Os efeitos das doses do fertilizante foram avaliados pela análise de regressão, adotando-se como critério para escolha do modelo a magnitude dos coeficientes de regressão significativos a $1 \%$ e $5 \%$ de probabilidade pelo teste $\mathrm{F}$, pelo programa computacional SAEG v.9.0 (RIBEIRO JÚNIOR; MELO, 2008).

\section{Resultados e Discussão}

$\mathrm{Na}$ Tabela 1 é apresentado um resumo da análise de variância dos dados dos componentes da produção de milho em resposta à utilização do fertilizante foliar. A aplicação do fertilizante teve efeito significativo sobre as variáveis altura das plantas, altura de inserção das espigas, número de grãos por espigas e produtividade. Não houve efeito significativo para as variáveis de diâmetro do colmo e da massa de 100 grãos.

Tabela 1. Quadrado médio e níveis de significância da altura das plantas (AP), diâmetro do colmo (DC), altura de inserção das espigas (AI), número de grãos por espigas (GPE), massa de 100 grãos (M100) e produtividade (P) de plantas de milho em função das doses do fertilizante. Dourados, MS, 2009.

\begin{tabular}{cccccccc}
\hline $\begin{array}{c}\text { Fonte de } \\
\text { Variação }\end{array}$ & $G L$ & $\begin{array}{c}A P \\
(\mathrm{~cm})\end{array}$ & $\begin{array}{c}D C \\
(\mathrm{~cm})\end{array}$ & $\begin{array}{c}A I \\
(\mathrm{~cm})\end{array}$ & GPE & $\begin{array}{c}M 100 \\
(\mathrm{gr})\end{array}$ & $\begin{array}{c}P \\
\left(\mathrm{~kg} \mathrm{ha}^{-1}\right)\end{array}$ \\
\hline Dose & 8 & $674,9244^{*}$ & $1,431977^{\text {NS }}$ & $674,4057^{* *}$ & $8917,494 * *$ & $8,757441^{\mathrm{Ns}}$ & $7066858,0^{* *}$ \\
Bloco & 3 & 285,6363 & 1,172541 & 59,25534 & 1035,641 & 11,51920 & 26880,84 \\
Erro & 24 & 90,99972 & 1,551045 & 79,16896 & 872,1972 & 8,920823 & 14773,96 \\
F & 7,417 & 0,988 & 8,519 & 10,224 & 0,982 & 478,332 \\
\hline C.V. $\%$ & & 4,045 & 5,849 & 7,510 & 6,321 & 10,239 & 1,172 \\
\hline
\end{tabular}

** Significativo a $1 \%$ de probabilidade pelo teste $\mathrm{F} ;{ }^{*}$ Significativo a $5 \%$ de probabilidade pelo teste $\mathrm{F}$; ${ }^{\text {NS }}$ Não significativo. Fonte: Elaboração dos autores.

Embora a massa de 100 grãos não tenha apresentado resposta significativa, pode-se observar que houve uma tendência de aumento em função das doses do fertilizante aplicado. Estes resultados enretanto não tiveram tanta influência na produção. Segundo os resultados de Silva et al. (2008) ao estudarem o efeito da aplicação de nitrogênio em cobertura no solo e zinco via foliar no milho safrinha em semeadura direta, em Campo Grande/ MS, também relataram que a massa de 100 grãos não foi modificada em função dos tratamentos. Segundo Gonçalves Júnior et al. (2007), entretanto, avaliaram os componentes da produção e a produtividade da cultura do milho, em função da adubação convencional com NPK e Zn, em dois solos de textura diferenciada, e concluíram que a adubação com NPK influenciou significativamente a massa de 1000 grãos. Da mesma forma, Ferreira et al. (2001) observaram aumento na massa de 100 grãos em função da aplicação de 0, 70, 140 e $210 \mathrm{Kg}$ ha $^{-1}$ de nitrogênio em cobertura. A disponibilidade de nutrientes proporcionada pela adubação foliar juntamente com os processos de transpiração e evaporação são responsáveis pelo movimento de água e nutrientes absorvidos pela planta, o que implicou em uma maior produtividade da cultura do milho, que pode explicar os aumentos nas variáveis estudadas, com aplicação das doses.

De maneira geral o nitrogênio é constituinte de muitos componentes da célula vegetal, incluindo 
aminoácidos e ácidos nucléicos, portanto o fornecimento de nitrogênio atua rapidamente no crescimento da planta como um todo (TAIZ; ZEIGER, 2009). Segundo os mesmos autores o fósforo é um componente integral de compostos importantes das células, incluindo fosfato-açúcares, intermediários da respiração e fotossíntese. Assim, o fornecimento de fósforo para planta garante uma maior eficiência fotossintética, e consequentemente maior acumulo de carboidratos e massa seca. Já o potássio é responsável pela regulação osmótica das plantas, também ativa inúmeras enzimas envolvidas na respiração e fotossíntese (TAIZ; ZAIGER, 2009). Neste contexto a adubação foliar com NPK + micronutrientes garantiu um bom desenvolvimento das plantas de milho, acarretando em uma produtividade.

O diâmetro do colmo não foi alterado em função das doses, assim como observado por Meira et al. (2009); Silva et al. (2008); Casagrande, Fornasieri Filho (2002) ao avaliarem o efeito de doses de N na cultura do milho. $\mathrm{O}$ aumento da quantidade disponível de água no solo, próximo da capacidade de campo, pode aumentar a produção de etileno pelas plantas, hormônio este que estimula a expansão do diâmetro do colmo (TAIZ; ZEIGER, 2009). Assim pelo fato do experimento ter sido instalado em um Latossolo Vermelhos distroférrico de estrutura granular, o que favorece a drenagem da água fornecida via irrigação para a cultura do milho, não houve produção excessiva de etileno, não alterando o diâmetro do colmo.

Em relação à altura de plantas, houve uma resposta quadrática em função do aumento das doses do fertilizante (Figura 1). Isto indica que o fertilizante NPK + micronutrientes fornecido via foliar na cultura do milho foi efetivamente absorvido e utilizado para o crescimento em altura das plantas. A maior altura foi obtida com a dose de $0,83 \mathrm{~L}$ $\mathrm{ha}^{-1}$, sendo que doses superiores promoveram um decréscimo da altura das plantas de milho. Conforme salientaram Ceretta, Silva e Pavinato (2007) as altas concentrações de fertilizantes foliares podem causar a desidratação dos tecidos (plasmólise), com influência no crescimento da planta. Para Deuner et al. (2008) estudando somente a influência da aplicação foliar de nitrogênio no acúmulo de proteínas e parâmetros de crescimento de plantas jovens de milho em comparação com a aplicação de ureia via solo, verificaram que não houve efeito significativo da forma de aplicação de ureia, na concentração de $0,5 \%$, para altura das plantas. No entanto, quando a concentração aumentou para $1,0 \%$ de ureia observaram que a adubação foliar proporcionou um incremento na altura das plantas $26 \%$ superior ao observado quando a adubação ocorreu via raiz.

Uma característica interessante observada neste experimento foi a resposta linear decrescente obtida na altura de inserção das espigas de milho, com máximo de 1,22 $\mathrm{m}$ na ausência do fertilizante e mínimo de 1,10 m com a dose de 2,0 $\mathrm{L} \mathrm{ha}^{-1}$ (Figura 2). Mar et al. (2003), trabalhando com cinco doses de $\mathrm{N}$ em milho safrinha, observaram que a altura máxima de inserção da espiga $(0,99 \mathrm{~m})$ foi obtida com a aplicação de $116,16 \mathrm{~kg} \mathrm{ha}^{-1} \mathrm{de} \mathrm{N}$, enquanto a altura máxima da planta $(2,10 \mathrm{~m})$, com a aplicação de 121,46 kg.ha-1 de N. Segundo Esteves, Corrêa e Araújo (1994) e Murakami (2000), maiores alturas de inserção das espigas e de planta podem predispor a mesma ao acamamento ou quebramento. Isto não ocorreu durante o período de realização do experimento, provavelmente pelo fato da maior altura de inserção da espiga ter ocorrido com a testemunha (sem aplicação de fertilizante líquido). Assim nesta pesquisa por ter se utilizado um híbrido duplo que apresenta como uma de suas características uma maior desuniformidade de altura de planta e inserção de espiga, apresentou variações entre os tratamentos. 
Figura 1. Altura de plantas de milho em função das doses do fertilizante. Dourados, MS, 2009. * é significativo a 5\% de probabilidade pelo teste $t$.

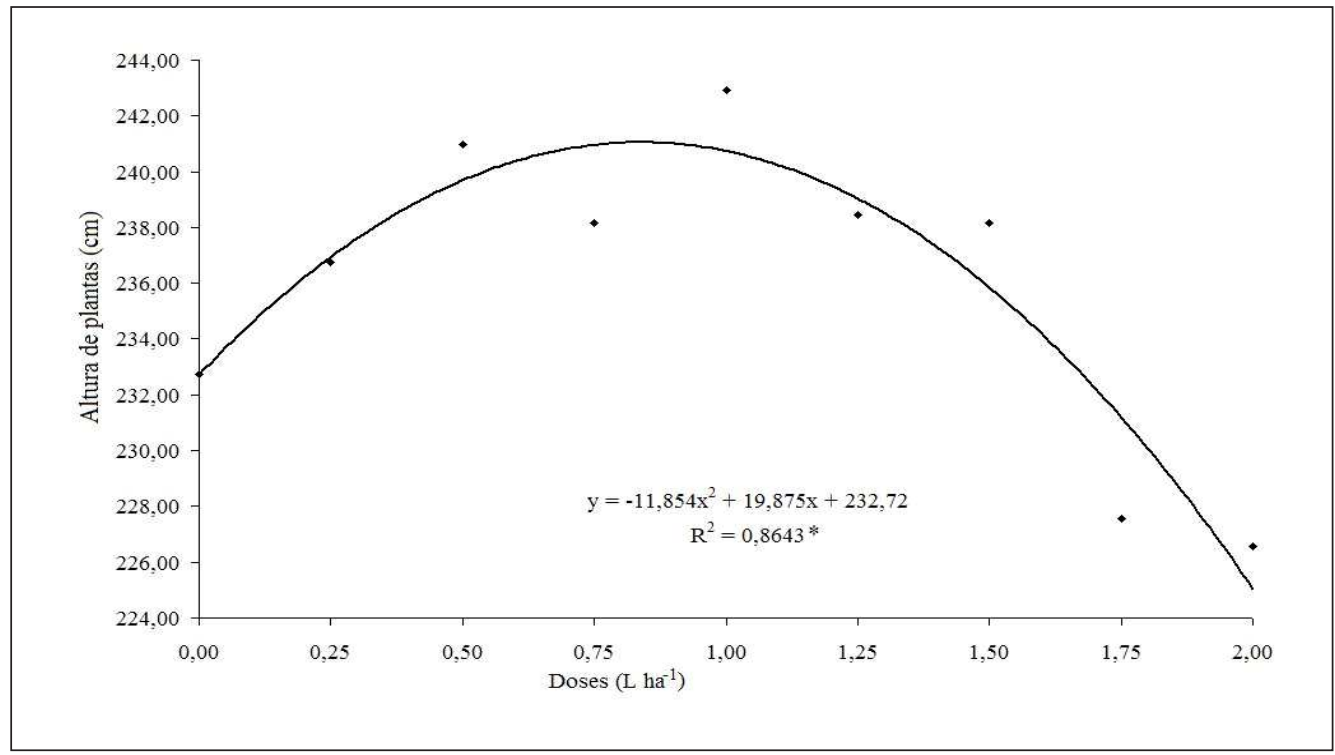

Fonte: Elaboração dos autores.

Figura 2. Altura de inserção das espigas de milho em função das doses do fertilizante. Dourados, MS, 2009. ** é significativo a $1 \%$ de probabilidade pelo teste $t$.

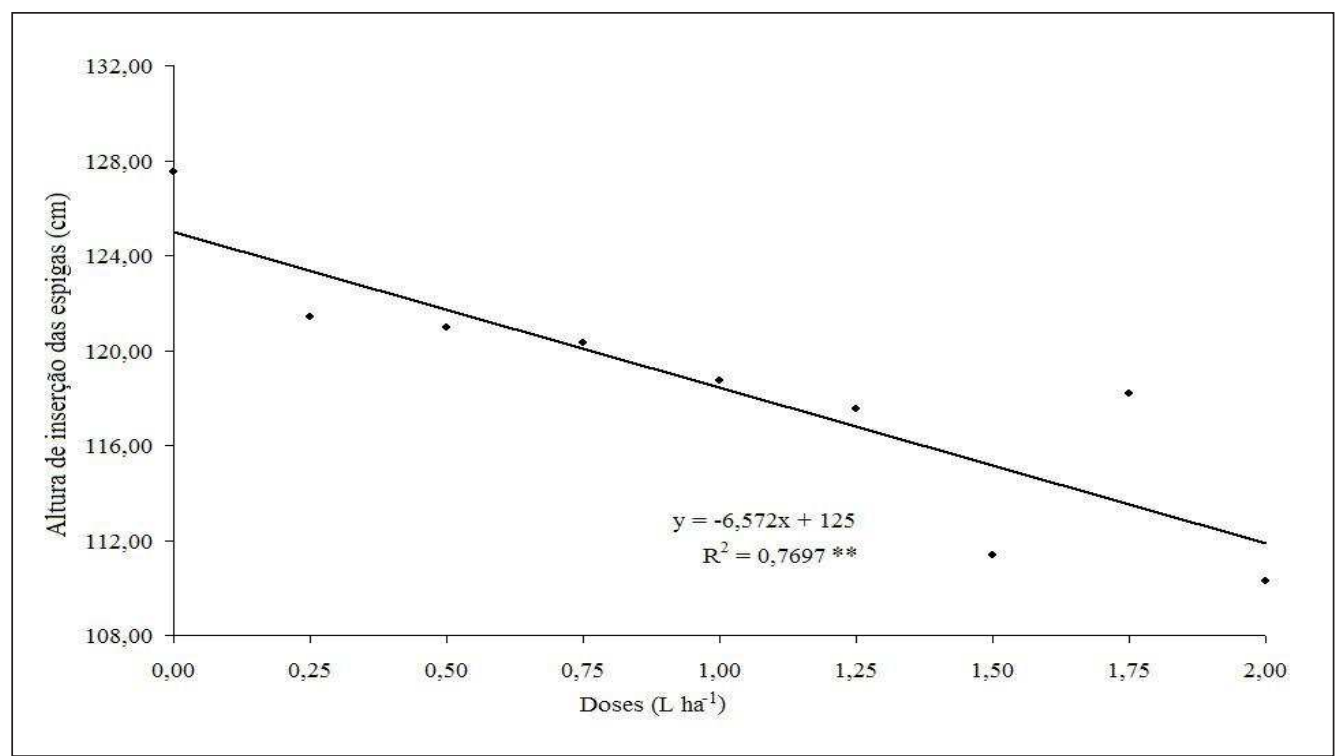

Fonte: Elaboração dos autores.

O número de grãos por espiga e a produtividade apresentaram uma resposta quadrática e altamente significativa (Figuras 3 e 4 , respectivamente) às doses aplicadas. A dose estimada de 1,15 L $\mathrm{ha}^{-1}$ do fertilizante foliar aplicado proporcionou uma produtividade máxima de $10.902 \mathrm{~kg} \mathrm{ha}^{-1} \mathrm{e}$ aproximadamente 486 grãos por espiga. Contudo, as doses superiores à estimada podem ter causado o antagonismo de nutrientes (apesar de não serem detectados sintomas visuais de fitotoxidade), visto a redução da produtividade, conforme observado na Figura 4. A produtividade máxima obtida neste 
trabalho é três vezes maior do que a sugerida pelo Instituto Agronômico de Pernambuco e a média brasileira, fato este explicado pelo fornecimento foliar de NPK, bons teores de micronutrientes presentes no solo do experimento e fornecimento de água via irrigação, o que proporcionou as melhores condições possíveis para o desenvolvimento da cultura, como o crescimento do sistema radicular que aumenta o volume de solo explorado e conseqüente ocorre maior e melhor absorção de nutrientes para a planta e aumento da fotossíntese liquida promovida pelo bom estado nutricional das plantas de milho.

Figura 3. Número de grãos por espigas de milho em função das doses do fertilizante. Dourados, MS, 2009. ** é significativo a $1 \%$ de probabilidade pelo teste $t$.

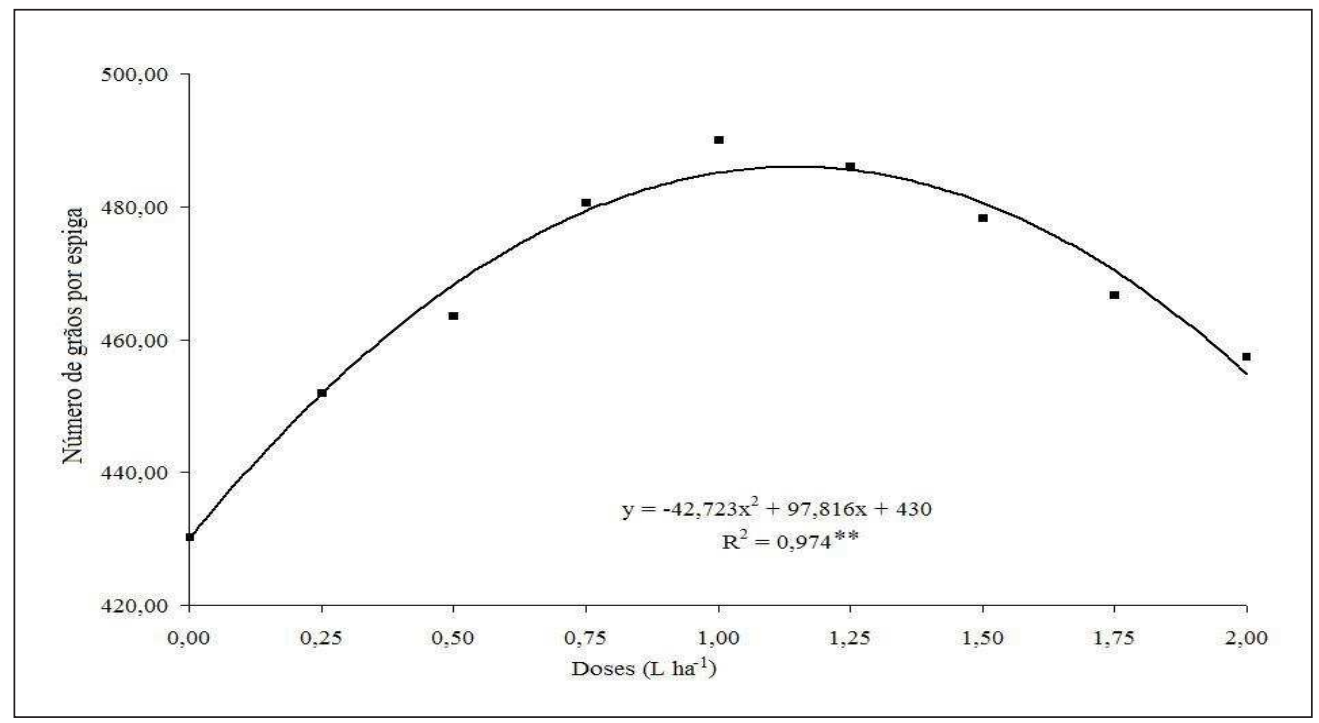

Fonte: Elaboração dos autores.

Figura 4. Produtividade do milho em função das doses do fertilizante. Dourados, MS, 2009. ** é significativo a 1\% de probabilidade pelo teste $t$.

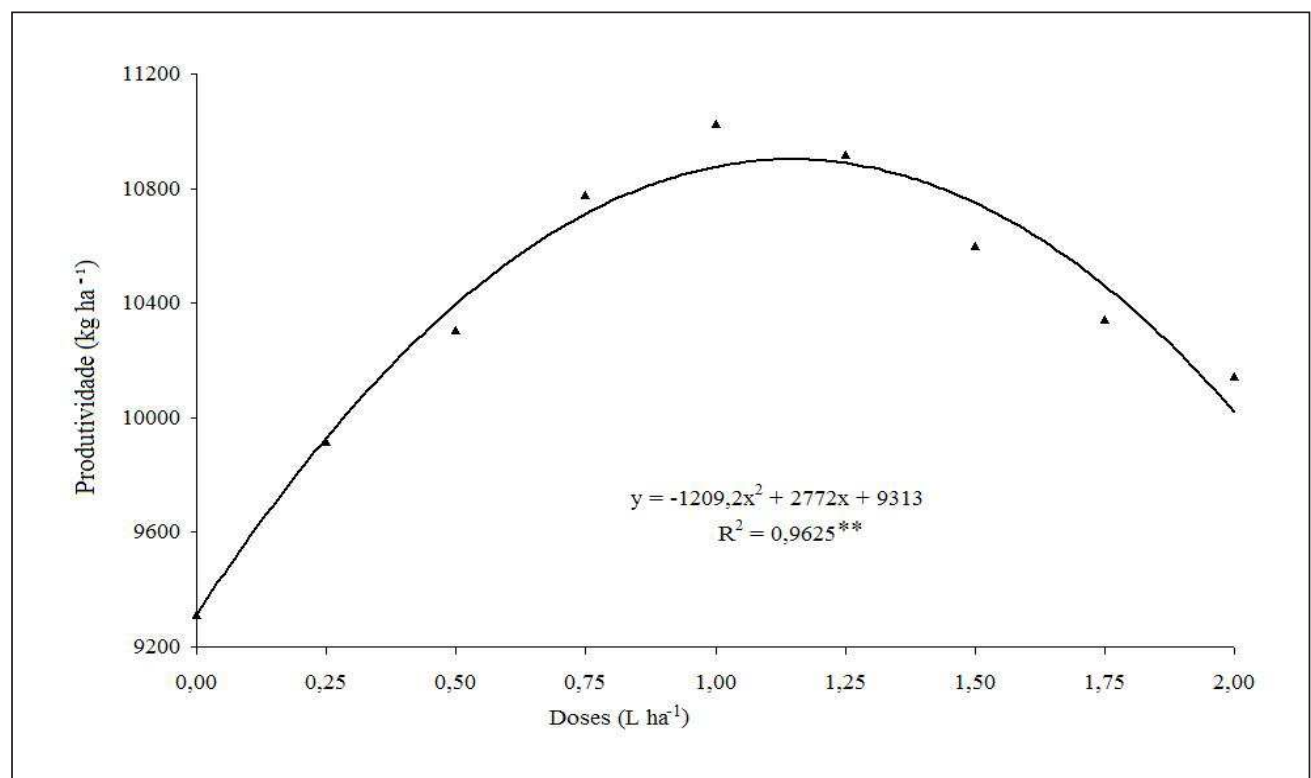

Fonte: Elaboração dos autores. 
Em lavouras irrigadas, podem-se aumentar os níveis de adubação, pois os riscos de perda de produtividade por déficit hídrico são minimizados (CERETTA; SILVEIRA, 2001). Conforme descrito por Cruz (2009), a baixa produtividade média de milho no Brasil (3.175 $\mathrm{kg} \mathrm{ha}^{-1}$ ) não reflete o bom nível tecnológico já alcançado por boa parte dos produtores voltados para lavouras comerciais, uma vez que as médias são obtidas nas mais diferentes regiões, em lavouras com diferentes sistemas de cultivos e finalidades. No trabalho realizado por Gonçalves Júnior et al. (2007), a adubação convencional com NPK também apresentou resposta positiva, aumentando os componentes número de grãos por espiga e a produtividade. Souza et al. (2003), estudaram a produtividade de grãos de milho irrigado em função de culturas antecessoras de inverno, nabo forrageiro e aveia preta e de doses de nitrogênio, (0, 60, 90 e $\left.120 \mathrm{~kg} \mathrm{ha}^{-1}\right)$ em uma área próxima ao do desenvolvimento deste experimento, obtiveram uma produtividade média de $7.093 \mathrm{~kg}$ ha1. Para o Instituto Agronômico de Pernambuco, uma boa produção de milho sob irrigação deverá iniciar com uma produtividade de $3.600 \mathrm{~kg} \mathrm{ha}^{-1}$.

\section{Conclusões}

A utilização do fertilizante líquido proporcionou a redução da altura de inserção das espigas, o aumento do número de grãos por espiga e da produtividade. A dose estimada de 1,15 $\mathrm{L} \mathrm{ha}^{-1}$ propiciou o maior número de grãos por espiga e a maior produtividade.

\section{Referências}

BERNARDO, S. Manual de irrigação. 5. ed. Viçosa: UFV, 1989. $596 \mathrm{p}$.

BERNARDO, S.; SOARES, A. A.; MANTOVANI, E. C. Manual de irrigação. 7. ed. Viçosa: UFV, 2005. 611 p.

BOARETTO, A. E.; PLÁCIDO NETO, S.; MURAOKA, T.; OLIVEIRA, M. W.; TRIVELIN, P. C. O. Fertilização foliar de nitrogênio para laranjeira em estágio de formação. Scientiae Agrícola, Piracicaba, v. 56, n. 3, p. 621-626, 1999.

BONO, J. A. M.; RODRIGUES, A. P. D. C.; MAUAD, M.; ALBUQUERQUE, J. C.; YAMAMOTO, C. R.; CHERMOUTH, K. S.; FREITAS, M. E. Modo de aplicação de fertilizantes nitrogenados na qualidade fisiológica de sementes de milho. Revista Agrarian, Dourados, v. 1, n. 2, p. 91-102, 2008.

CARVAlHO, M. A. C.; PAUlinO, H. B.; ENES JÚNIOR, F.; BUZETTI, S.; SÁ, M. E.; ATHAYDE, M. L. F. Uso da adubação foliar nitrogenada e potássica no algodoeiro. Bragantia, Campinas, v. 60, n. 3, p. 239-244, 2001.

CASAGRANDE, J. R. R.; FORNASIERI FILHO, D. Adubação nitrogenada na cultura do milho safrinha. Pesquisa Agropecuária Brasileira, Brasília, v. 37, n. 1, p. 33-40, 2002.

CERETTA, C. A.; SILVA, L. S. da; PAVINATO, A. Manejo da adubação. In: NOVAIS, R. F.; ALVAREZ V., V. H.; BARROS, N. F.; FONTES, R. L. F.; CANTARUTTI, R. B.; NEVES, J. C. L. (Ed.). Fertilidade do solo. Viçosa: SBCS, 2007. p. 851-872.

CERETTA, C. A.; SILVEIRA, M. J. Manejo da fertilidade do solo para altas produtividades. In: CARLESSO, R. (Ed.). Irrigação por aspersão no Rio Grande do Sul. Santa Maria: UFSM, 2001. p. 10-20.

COELHO, A. M.; CRUZ, J. C.; PEREIRA FILHO, I. A. Desafios para obtenção de altas produtividades de milho. In: CONGRESSO NACIONAL DE MILHO E SORGO, 25., 2004, Cuiabá. Anais... Cuiabá: ABMS/Embrapa Milho e Sorgo/Empaer, 2004. CD-ROM.

CRUZ, J. C. (Org.). Sistemas de produção, 2. Versão eletrônica. 4. ed. Sete Lagoas: Embrapa, 2008. Disponível em: <http://www.cnpms.embrapa.br/publicacoes/milho/ index.htm>. Acesso em: 13 set. 2009.

DEUNER, S.; NASCIMENTO, R.; FERREIRA, L. S.; BADINELLI, P. G.; KERBER, R. S. Adubação foliar e via solo de nitrogênio em plantas de milho em fase inicial de desenvolvimento. Ciência e Agrotecnologia, Lavras, v. 32, n. 5, p. 1359-1365, 2008.

DÖBEREINER, J.; BALDANI, V. L. D.; BALDANI, J. I. Como isolar e identificar bactérias diazotróficas de plantas não leguminosas. Brasília, DF: Embrapa-SPI; Itaguaí: Embrapa-CNPAB, 1995. 60 p.

ESTEVES, A.; CORRÊA, L. A.; ARAÚJO, N. B. Avaliação de cultivares de milho (Zea mays L.) de ciclo superprecoce, na entressafra. In: CONGRESSO NACIONAL DE MILHO E SORGO, 20., 1994, Goiânia. Resumos. Goiânia: ABMS/EMGOPA/CNPMSEMBRAPA/UFG/EMATER-GO, 1994. p. 38. 
FANCELLI, A. L.; DOURADO NETO, D. Produção de milho. Guaíba:Agropecuária, 2000. 360 p.

FERREIRA, A. C. B.; ARAÚJO, G. A. A.; PEREIRA, P. R. G.; CARDOSO, A. A. Características agronômicas e nutricionais do milho adubado com nitrogênio, molibdênio e zinco. Scientia Agricola, Piracicaba, v. 58, n. 1, p. 131-138, 2001.

GONÇALVES JÚNIOR, A. C.; TRAUTMANN, R. R.; MARENGONI, N. G.; RIBEIRO, O. L.; SANTOS, A. L. Produtividade do milho em resposta a adubação com NPK e Zn em Argissolo Vermelho-amarelo eutrófico e Latossolo Vermelho eutroférrico. Ciência e Agrotecnologia, Lavras, v. 31, n. 4, p. 1231-1236, 2007.

MAR, G. D.; MARCHETTI, M. E.; SOUZA, L. C. F.; GONÇALVES, M. C.; NOVELINO, J. O. Produção do milho safrinha em função de doses e épocas de aplicação de nitrogênio. Bragantia, Campinas, v. 62, n. 2, p. $267-$ 274, 2003.

MEIRA, F. A.; BUZETTI, S.; ANDREOTTI, M.; A. R. F.; O.; SÁ, M. E.; ANDRADE, J. A. C. Fontes e épocas de aplicação do nitrogênio na cultura do milho irrigado. Semina: Ciências Agrárias, Londrina, v. 30, n. 2, p. $275-$ 284, 2009.

MURAKAMI, D. M. Comportamento de alguns híbridos comerciais de milho (Zea mays L.) na Região Sul do Estado de Mato Grosso, safrinha 1997. In: CONGRESSO NACIONAL DE MILHO E SORGO, 23., 2000, Uberlândia. Resumos... Uberlândia: ABMS/EMBRAPA MILHO SORGO/UFU, 2000. p. 108.

RAUN, W. R.; JOHNSON, G. V. Improving nitrogen use efficiency for cereal production. Agronomy Journal, Madison, v. 91, n. 3, p. 357-363, 1999.
RIBEIRO JUNIOR, J. I.; MELO, A. L. P. Guia prático para utilização do SAEG. Viçosa: Folha Artes Gráficas Ltda., 2008. v. 1, 288 p.

SANGOI, L.; SILVA, P. R. F.; ARGENTA, G. Arranjo espacial e plantas e milho: Como otimiza-lo para maximizar o rendimento. In: CONGRESSO NACIONAL DE MILHO E SORGO, 25, 2004. Anais... Cuiabá: ASBMS, 2004. p. 150-159.

SCHRÖDER, J. J.; NEETESON, J. J.; OENEMA, O.; STRUIK, P. C. Does the crop or the soil indicate how to save nitrogen in maize production: reviewing the state of art. Field Crops Research, Amsterdam, v. 66, n. 1, p. 151-164, 2000.

SILVA, T. R. B.; GUZELLA, R. E.; FREITAS, L. B.; MAIA, S. C. M. Efeito da aplicação de nitrogênio em cobertura e zinco via foliar no milho safrinha em semeadura direta. Revista Agrarian, Dourados, v. 1, n. 2 , p. 59-69, 2008.

SOUZA, L. C. F.; FEDATO, E.; GONÇALVES, M. C.; ALVES SOBRINHO, T.; HOOGERHEIDE, H. C.; VIEIRA, V. V. Produtividade de grãos de milho irrigado em função da cultura antecessora e de doses de nitrogênio. Revista Brasileira de Milho e Sorgo, Sete Lagoas, v. 2, n. 2, p. 44-51, 2003.

TAIZ, L.; ZEIGER, E. Fisiologia vegetal. 4. ed. Porto Alegre: Armed, 2009. 848 p.

VON PINHO, R. G.; RIVERA, A. A. C.; BRITO, A. H.; LIMA, T. G. Avaliação agronômica do cultivo de milho em diferentes níveis de investimento. Ciência e Agrotecnologia, Lavras, v. 33, n. 1, p. 39-46, 2009.

YAMADA, T.; ABDALLA, S. R. S.; VITTI, G. C. Nitrogênio e enxofre na agricultura brasileira: simpósio sobre nitrogênio e enxofre na agricultura brasileira. Piracicaba: [s. n.], 2007. 722 p. 
